\title{
RESEARCH PAPER \\ EFFECT OF SOME AGRONOMIC PRACTICES TO INCREASE MAIZE YIELD IN GHANA
}

\author{
P. Akowuah ${ }^{1}$, J. Sarkodie-Addo ${ }^{2}$ and K. Boa ${ }^{3}$ \\ ${ }^{1}$ Ministry of Food and Agriculture \\ ${ }^{2}$ Dept of Crop Science, KNUST, Kumasi \\ ${ }^{3}$ P.O. Box 23, Nkawie-Toase
}

\begin{abstract}
Low plant densities of maize are often observed in fields of farmers practising no-till agriculture which causes low grain yield in Ghana. With the increasing population and consumption of maize in the country, research must be directed to solve this problem to enhance maize production. In this paper, a $2 x 3$ factorial experiment in randomized complete block design with 4 replications was carried out at Wioso in the Atwima-Nwabiagya District in the Ashanti Region of Ghana during the major season of 2007 in order to come out with the best practices in maize production. The objectives of the study were to determine the right period of refilling maize field and the comparative effect of refilling with seed and seedling on the growth, optimum population density, and yield of maize. The factors were material for refill, which was either seeds or seedlings, and time of refilling either at 5, 10, and 15 days after planting. The results showed that refilling with seedlings produced the greatest positive effect in the number of leaves per plant, leaf length, leaf diameter, plant height and stem girth. Furthermore, refilling with seedlings contributed more to the optimum plant population density. Total grain yield when seedlings were used as refill was $967 \mathrm{~kg}$ per hectare more than when seeds were used as refill material. On the other hand, plants from seeds refill were weak, lodged more and allowed much solar radiation penetration to the ground. Grain yield from seed refill plants was $6 \%$, whilst seedling refill plants contributed $34 \%$ to the total grain yield. Refilling at 5 days after planting induced greater growth than 10 or 15 days after planting. The results indicate that it is possible to do refilling in maize field by using seedling as this contributes more than the traditional method of using seeds.
\end{abstract}

Keywords: grain yield, refill material, sun fleck, time of refilling

\section{INTRODUCTION}

Maize is considered to be the most important cereal in Ghana accounting for $74 \%$ of the total cereals (maize, rice, sorghum and millet) produced in 2005 (MOFA, 2005). The total area under maize cultivation in 2005 was about
740,000 ha and production was estimated as 1 , 171,000 metric tons (MOFA, 2006). The everincreasing human population together with practices such as slash and burn, and the recent proliferation of surface mining has endangered shifting cultivation as practiced in the past by 
most farmers, as a means of conserving the soil and maintaining productivity (Ekboir et al., 2002). Due to the above reasons, farmers continue to grow maize on the same piece of land season after season, in addition to practicing the slash and burn method that had contributed to the increasing land degradation. There is therefore the need to provide safe interventions for farmers to produce sustainably.

The use of no-till technology conserves moisture by reducing evaporation and runoff, increases infiltration of water and decreases soil temperature fluctuations. It also supplies nutrients and organic matter from decomposing mulch and improve soil faunal activity (Goddard et al., 2008). Boahen et al. (2007) stated that the no-till concept is for resourcesaving agricultural production that strives to achieve an acceptable profit together with high and sustained production levels while concurrently conserving the environment. Bonsu (2001) stated that residues left on the field during no-till serve as mulch which protects the soil from soil erosion and limit weed growth throughout the growing season.

Farmers traditionally attempt to replace the ungerminated maize by re-seeding at the same spot or hill of dead plant(s). However, these late germinated plants suffer a number of unfavorable growth conditions (Asiedu et al., 2001; Van Gassel et al., 1996). Attempts by some individuals and institutions to improve plant population density in No- till fields have been done using date of planting, refilling with seed maize, planting depth, insecticide and fungicide treatment, firming planting spot and planting through mulch. These were developed to protect planting spot from the rodents, yet farmers continue to encounter loss of plant stands in their maize fields including through destruction of seeds by rodents and seed borne pathogens.

The objectives of this study were to determine comparative effect of refilling with seed and seedling as well as time of refilling on the growth, optimum population density, and grain yield of maize.

\section{MATERIALS AND METHODS}

The experiment was conducted at NkawieWioso in the Atwima Nwabiagya District of Ashanti Region. General soil characteristics in the study area vary from well drained with high organic matter content to poor drained with low organic matter content. The soil is a well drained loamy soil of density ranging from 1.38 -1.6 and porosity from $0.39-0.48$. The annual precipitation ranges between $1400 \mathrm{~mm}$ and 1800mm (Atwima Nwabiagya District Assembly 1996).

\section{Land preparation}

The experiment was $2 \times 3$ factorial with treatments arranged in a randomized complete block design. Refilling materials were seeds and seedlings and time of refilling at 5, 10 and 15 days after initial planting. A post germination herbicide (Glyphosate) was used to spray the weeds, with the use of knapsack sprayer fitted with a low volume nozzle at the rate of $300 \mathrm{ml}$ per 15 litres of water. The plant residues were left on the soil surface without burning for 7 days before planting.

\section{Planting}

The experimental plot was planted on $28^{\text {th }}$ April, 2007 at the spacing of $80 \mathrm{~cm} \times 40 \mathrm{~cm}$ with 2 seeds per hill; seeds were planted directly through the mulch. Maize seed was protected from predators by using seed plus (Imidacloprid 20\%, Metalaxyl 20\% and Anthraquinone $4 \%$ ) for seed treatment at the rate of $10 \mathrm{~g}$ active ingredient per $1 \mathrm{~kg}$ seed. Each plot had 6 rows with 12 hills, giving a total of 144 plants per plot.

Five days after planting $25 \%$ losses of the germinated plants were deliberately created through randomly uprooting 36 plants out of 144 plants. A plot in each replication was refilled with seed and another plot with seedlings. The seeds for seedlings to be used were planted the same day as the experimental plot to enable the use of seedlings of the same age to mini- 
mize competition among growing plants. Seedlings were planted with a ball-of-earth at the base, a condition meant to reduce stress at transplanting. The refilling process using maize seeds and seedlings were repeated at 10 days ( $8^{\text {th }}$ May) and 15 days ( $13^{\text {th }}$ May) after initial planting of the experiment.

According to GGDP (1998) maize can tolerate moisture stress better during the early period of plant growth than later growth. Thus 15 days period for refilling particularly with maize seedling, was chosen for this experiment.

Starter fertilizer (NPK) $125 \mathrm{~kg} / \mathrm{ha}$ was applied at planting and Urea fertilizer was also applied 4 weeks after planting at $62.5 \mathrm{~kg} / \mathrm{ha}$. Preemergence herbicide (Atrazine WP) was applied on the second day after planting. Hand picking of secondary weeds mostly Panicum maximum was done 7 days after planting.

\section{Data collection and analyses}

Parameters measured were number of leaves per plant, leaf length, leaf width, Sun fleck using ceptometer, plant height, stem girth, and refilled plants establishment; these were measured at tasseling. Others were plants population, grain yield and percentage contribution of grain yield from refilled plants, all of which were measured at harvesting. The data was analyzed using the Analysis of Variance technique and the MSTATC statistical package. The least significant difference at $5 \%$ probability was used to determine treatment differences.

\section{RESULTS AND DISCUSSIONS \\ Number, length and width of leaves}

Table 1 shows the effect of refilled material and refilling on the number of leaves, leaf length and leaf width of the maize plants. The results showed that refilling with seedlings produced the greater number of leaves per plant (12.58), which was significantly higher than that produced with seeds as refill material. Time of refilling significantly affected $(\mathrm{P}<0.05)$ leaf production. Refilling at 5days after planting resulted in plants producing the largest number of leaves, which was significantly higher than when refilling was done at 10 and 15 days. Plants refilled at 10 days also produced significantly greater number of leaves than when refilling was done at 15 DAP.

Refilling with seedlings produced significantly $(\mathrm{P}<0.05)$ longer leaf $(94.0 \mathrm{~cm})$ than when seed were used to do refill (Table 1). Time of refill also significantly $(\mathrm{P}<0.05)$ affected maize leaf length with the treatment effect of refilling at 5 days being significantly higher than all other treatment means. However, treatment effects between refilling at 10 and 15 DAP showed no statistical differences.

Leaf width was greatest $(9.52 \mathrm{~cm})$ when refilling was done using seedlings, and this effect was significantly higher than using seeds (Table 1). Leaf width of plants was also significantly affected by time of refilling. Refilling at 5 DAP produced greater effect than all other treatments, whilst refilling at 10 DAP also produced significantly higher leaf width than for the 15 DAP.

\section{Sun fleck, plant height and stem girth}

Table 2 shows the effect of refilled material and refilling time on sun fleck, plant height and stem girth of the maize plants. Results of material used on sun flecks (potential of allowing sunlight to pass through canopy) showed that using seeds as refill material led to significant loss of solar radiation than using seedlings. Indeed, $40 \%$ of sunlight that could have been used by the plants was lost. Time of refilling did not, however, significantly affect $(\mathrm{P}>0.05)$ sun fleck measurement.

Mean height of plants when seedlings were used as refill material was significantly higher $(\mathrm{P}<0.05)$ than when seeds were used as refill material. Time of refill significantly affected maize plant height. The tallest plants $(151.0 \mathrm{~cm})$ were measured following refilling at 5 DAP, which statistically was similar to that at 10 DAP treatment effect, but either effect was significantly higher $(\mathrm{P}<0.05)$ than that of refill- 
Table 1: Effect of refilled material and refilling time on number of leaves, leaf length and leaf diameter of maize plants.

\begin{tabular}{lccl}
\hline Treatment & Leaf Number Plant $^{-1}$ & Leaf Length $(\mathbf{c m})$ & Leaf Width $(\mathbf{c m})$ \\
\hline Refill material & & & \\
Seed & 9.67 & 78.6 & 6.83 \\
Seedling & 12.58 & 94.0 & 9.29 \\
LSD (5\%) & $\mathbf{0 . 6 7}$ & $\mathbf{7 . 3 6}$ & $\mathbf{0 . 6 9}$ \\
& & \\
Time of Refilling & & & \\
5 days & 12.25 & 94.1 & 9.52 \\
10 days & 11.12 & 84.2 & 7.93 \\
15 days & 10.00 & 80.6 & 6.73 \\
LSD (5\%) & $\mathbf{0 . 8 5}$ & $\mathbf{9 . 0}$ & $\mathbf{0 . 8 5}$ \\
CV $(\%)$ & $\mathbf{7 . 0}$ & $\mathbf{9 . 8}$ & $\mathbf{9 . 9 0}$ \\
& & & \\
\hline
\end{tabular}

Table 2: Effect of refilled material and refilling time on Sun flecks, plant height and stem girth of maize plants.

\begin{tabular}{llcl}
\hline Treatment & Sun fleck & Plant Height $(\mathbf{c m})$ & Stem Girth $(\mathbf{c m})$ \\
\hline Refill material & & & \\
Seed & 12.47 & 95.2 & 1.41 \\
Seedling & 7.01 & 154.6 & 2.00 \\
LSD $(\mathbf{5 \%})$ & $\mathbf{3 . 7 9}$ & $\mathbf{1 4 . 5}$ & $\mathbf{0 . 2}$ \\
& & & \\
Time of Refilling & & 151.0 & 1.98 \\
5 days & 8.56 & 146.0 & 1.66 \\
10 days & 10.11 & 109.1 & 1.48 \\
15 days & 10.54 & $\mathbf{1 7 . 8}$ & $\mathbf{0 . 2 5}$ \\
LSD $(\mathbf{5 \%})$ & $\mathbf{N S}$ & $\mathbf{1 3 . 4}$ & $\mathbf{1 4 . 1}$ \\
CV $(\%)$ & $\mathbf{4 4 . 8}$ & & \\
\hline
\end{tabular}

ing at 15 DAP.

Girth of plants from seedlings refill was significantly higher $(\mathrm{P}<0.05)$ than that from seeds. Stem girth was also significantly affected by time of refilling with the treatment effect of refill at 5 DAP being significantly higher than all other treatment effects. Treatment differences between refilling at 10 and 15 DAP were, however, not significant.
Plant establishment, lodging and plant population

Table 3 shows the effect of refilled material and refilled time on plant establishment, lodging and plant population of the maize plants. Refilled plant established with seedling was significantly higher than using seeds. Difference was about $30 \%$ greater than when refilling was done with seeds. Time of refilling did not significantly $(\mathrm{P}>0.05)$ affect plant establishment. 
Table 3: Effect of refilled material and refilling time on plant establishment, lodging and plant population of maize plants

\begin{tabular}{lccc}
\hline Treatment & $\begin{array}{c}\text { Plants established } \\
\left(\mathbf{h a}^{-1}\right)\end{array}$ & $\begin{array}{c}\text { Plants lodged } \\
\left(\mathbf{h a}^{-1}\right)\end{array}$ & $\begin{array}{c}\text { Plant population } \\
\left(\mathbf{h a}^{-1}\right)\end{array}$ \\
\hline Refill material & & & \\
Seed & 10938 & 294 & 53438 \\
Seedling & 14354 & 132 & 58229 \\
LSD (5\%) & $\mathbf{1 7 1 5 . 1}$ & $\mathbf{0 . 0 2}$ & $\mathbf{2 3 5 5}$ \\
& & & \\
Time of Refilling & & 190 & 57812 \\
5 days & 13375 & 204 & 53906 \\
10 days & 13125 & 196 & 55781 \\
15 days & 11438 & $\mathbf{0 . 0 3}$ & $\mathbf{N S}$ \\
LSD (5\%) & $\mathbf{N S}$ & $\mathbf{1 2 , 0}$ & $\mathbf{4 . 8}$ \\
CV $(\%)$ & $\mathbf{1 5 . 6}$ & & \\
\hline
\end{tabular}

Plant lodging was significantly higher when seeds were used to do refilling. Time of refill also significantly affected plants lodging. The greatest effect was recorded when refilling was done at 10 DAP, and this was significantly higher than all other treatment effects. Lodging was also significantly greater at refilling at 15 DAP than at 5 DAP.

Refilling with seedlings resulted in a significantly higher plants population (58229.0 plants/ ha) than using seeds (53438.0 plants/ha). Time of refilling did not significantly affect plant population, although the greatest effect 57812.0 plants/ha, was recorded when refilling was done at 5 DAP.

\section{Grain yield}

Table 4 shows the effect of refilled material and time of refilling on total grain yield of the maize plants. Total grain yield difference between refill with seedling and seed was significant, and this was about $30 \%$ or nearly $1 \mathrm{t} / \mathrm{ha}$. However, time of refilling did not significantly affect maize grain yield.
Both material and time of refilling did not significantly affect $(\mathrm{P}>0.05)$ grain yield from refilled plants, but while $34 \%$ of the grain was produced from refilling with seedlings, only $6 \%$ was contributed when refilling was done with seeds.

\section{DISCUSSION}

Effect of refilling material on maize growth

The response of maize growth to the type of refilling material, either with seed or with seedlings showed that in the majority of the parameters measured, refilling with seedlings gave a significantly greater response than using seeds as the refilling material. Results showed that the number of leaves from plants refilled with seedlings was $30 \%$ greater than when seeds were used as refilling material (Table 1). In addition, leaf length of plants from seedling refill was $20 \%$ greater than when refilling was done with seeds. Furthermore, leaf diameter from seedling refill was about $30 \%$ greater than using seeds as refilled material. The ability to support greater leaf production is an indication that if growth resources are available through- 
Table 4: Effect of refilled material and time of refilling on total grain yield and grain yield from refilled material

\begin{tabular}{lcc}
\hline Treatment & Total Grain Yield (kg/ha) & $\begin{array}{c}\text { Grain Yield from refilled } \\
\text { material (\%) }\end{array}$ \\
\hline Refilled material & & \\
Seed & 7,469 & 6.6 \\
Seedling & 8,436 & 34.3 \\
LSD $(\mathbf{5 \% )}$ & $\mathbf{7 1 2}$ & $\mathbf{N S}$ \\
& & \\
Time of Refilling & & \\
5 days & 7,820 & 16.4 \\
10 days & 8,037 & 36.5 \\
15 days & 8,001 & 8.5 \\
LSD $(\mathbf{5 \% )}$ & $\mathbf{N S}$ & $\mathbf{N S}$ \\
CV $(\%)$ & $\mathbf{1 0 . 3}$ & $\mathbf{8 6 . 9}$ \\
\hline
\end{tabular}

out the growing season, growth and yield would be enhanced. This is because photosynthesis in such plants would be greater (Gardner et al., 1985; Agyei-Wiredu, 1996; Hopkins, 1993).

Penetration of light through the plants, as measured by sun fleck (Table 2) was greater in plants from refilling with seeds than those from seedling. This is not surprising since plants from seed refill were smaller with less leaf area or source capacity than those from seedlings used as refill. In crop production, this is a set back, as much solar energy would be lost in such conditions, and consequently grain yield would be reduced (Gardner et al., 1985; Hopkins, 1999).

Plant height and stem girth of plants from seedling refill were $62 \%$ and $43 \%$ greater than those from seed refill, respectively. Taller plants can compete well with weeds and other crops for solar radiation. In the peasant farming system, where mixed cropping is the most common crop production system, this would be an advantage for higher maize production. Normally, in such a system, several crops are grown and maize is harvested early to offset any hunger, pending the maturity of the other crops, especially plantain and the root and tuber crops.

The greater stem girth of plants from seedling refill (Table 2) presumably reduced plant lodging (Table 3). Lodging was greater, indeed more than $100 \%$, in plants using seeds as refilling than using seedlings. Despite the taller plants produced from the latter treatment (Table $2)$, lodging was still lower. The importance of reduced lodging in maize yields cannot be over -emphasized. Lodging reduced plants ability to absorb solar radiation and photosynthates production and results in lower grain yield. Furthermore, greater lodging means carrying out farming operations as weed and pest control and fertilizer application can be dangerous and expensive (Boa-Amponsem, 2000).

Plant survival was also significantly affected by refilling materials (Tables 3 ). Refilling with seedlings contributed more than $40 \%$ to the total plant population compared with when refilling was done with seeds. In crop yield, the contribution of each individual plant counts. Thus, without much effort and probably at no extra cost, if doing refilling in maize product- 
ion with seedlings can be so advantageous, adopting it would increase farmers' yield.

\section{Effect of refilling material on maize yield}

Total maize grain yield was significantly affected by the refill materials (Table 4). Using seedlings as refill material supported significantly greater $(\mathrm{P}<0.05)$ grain yield than using seed. Indeed grain production in the former treatment was almost $1000 \mathrm{~kg}$ greater than in the latter treatment per hectare. Furthermore, seedlings used to refill contributed more than $34 \%$ to the total grain yield.

Statistic on maize cultivation in Ghana indicated that total land area sown to maize in 2005 was 740000 ha. The estimated yield for that year was 1,710,000 metric tons (SRID, MOFA, 2005). The present result showed that if farmers would use seedlings to do refilling instead of seed, which is the current practice, yield per hectare would increase by about $1000 \mathrm{~kg} \mathrm{ha}^{-1}$.

\section{Effect of time refilling on maize growth and yield}

Maize growth and yield were affected by the time when refilling was done whether with seedlings or seeds. In all the growth parameters measured, result indicated that, doing refilling at 5 days after planting showed the greatest response. In a similar pattern, better responses were recorded in doing refilling at 10 days rather than at 15 days after planting. Indeed, delay in refilling resulted in weak plants, reduced leaf length, diameter and stem girth. Delayed refilling resulted in overshadowing by established plants, as a result sun fleck measurements were higher and such plants recorded greater rates of lodging. Grain yield results were, however, not consistent with the growth measurement.

The general practice of peasant farmers had been to refill with seeds following planting of their crop. Commonly, plants from such refill are weak and become less competitive with established plants and weeds. Many times yield recorded by such plants is uneconomical, and at times no grains are produced from such plants. The present study has demonstrated that refilling in maize production can be achieved by using seedlings, and that such plants are vigorous, grow better, lodge less and ultimately would produce acceptable economic yield rather than doing refilling with seeds.

\section{CONCLUSION}

Results showed that it is possible to use maize seedlings to fill vacancies created in maize farms from failure of germination or destruction of seedlings by pests. This practice appears more profitable than the traditional method of using seeds, as plants from such practice competed well with established plants and contributed significantly to total grain yield. The results also showed that refilled plants demonstrated greater growth when refilling was done at 5 days after planting.

\section{REFERENCES}

Agyei-Wiredu, P. (1996). Effect of leaf development on growth and yield of cowpea varieties. BSc thesis, Kwame Nkrumah University of Science and Technology, Kumasi.

Asiedu, E .A., Gregg, B. R., Djokoto, I. and Van Gassel, A. R. J. (2001). WASDU Seed Saver Drying-Packaging System

Atwima Nwabiagya District Assembly (2006). District Medium Term Development Plan (2006-2009)

Boa-Amponsem, K. (2000). No-till Annual Report Mimeo CSIR-CRI, Kumasi, Ghana.

Boahen, P., Asare, B. E. and Ashburner, J. (2007). Conservation Agriculture as practiced in Ghana. $11 \mathrm{pp}$.

Bonsu, M. (2001). Conservation Agriculture in Ghana. Country Report prepared for FAO Regional Office for Africa.

Ekboir, J., Boa-Amponsem, K. and Enkyi, A. A. (2005). Impact of no-till Technologies in 


\section{Ghana. Mexico D. F. CIMMYT}

Gardner, F., Pearce. R. B. and Mitchell, R. L. (1985). Physiology of Crop Plants. Iowa State Univ. Press, Ames, IA, 323 pages.

GGDP (1998). Ghana Grain and legumes development project, Maize and Legumes Production Guide.

Goddard, T., Ellis, Y. W. and Watson, S. (2008). World Association Soil and Water Conservation (WASWC), No-tillage Farming System.
Hopkins, W. G. (1999). Introduction to Plant Physiology. John Wiley and Sons, Inc. New York. 521 pages.

MOFA. (2005). Ministry of Food and Agriculture, Monitoring and Evaluation report for 2005, Ashanti Region.

MOFA. (2006). Ministry of Food and Agriculture Sector Development Policy FASDEP II.

Van Gastel, A. J. G., Pagnotta, M. A. and Poceddu, T. (1996). Seed Science and Technology. Proceedings of a Train-the Trainers workshop. ICARDA, Aleppo. Syria, 311 pp. 